\title{
PERSEPSI KENYAMANAN DAN HARGA TERHADAP MINAT PENGGUNAAN JASA TRANSPORTASI ANGKUTAN UMUM KOTA DI KABUPATEN PURWAKARTA
}

\author{
Oleh : \\ Ade Nurhayati Kusumadewi \\ Prodi Manajemen - STIE DR KHEZ Muttaqien \\ adenurhayatikd@gmail.com
}

DOI Artikel : https://doi.org/10.34308/eqien.v7i1.108

\begin{tabular}{l} 
Article Info \\
\hline Article History : \\
Received 10 Feb - 2020 \\
Accepted $20 \mathrm{Feb}-2020$ \\
Available Online $28 \mathrm{Feb}-$ \\
2020
\end{tabular}

Keyword:

Comfort Perception,

Price, Buying Interest

\begin{abstract}
Reduced interest in the use of city public transport services because there are still many public transport facilities that do not attach importance to the convenience of service users and the absence of alternative tariff options for long distance or short distance, so service users choose to use other transportation services that can answer their needs, such as transportation online that already exists in Purwakarta today. In this case the author is very interested in conducting research, with the title "The Influence of Perceptions of Comfort and Price Against Interest in the Use of City Public Transportation Transportation Services in Purwakarta District". The purpose of this study was to determine the effect of perceived comfort and price on the interest in using the City Public Transport Service in Purwakarta Regency. In this study respondents were users of public transportation services in Purwakarta using sampling techniques called Non-Probability Sampling. The research method used is descriptive qualitative method, which is a method that is done by collecting, presenting and analyzing data that gives a clear enough picture of the object under study. This study uses a multiple linear regression analysis model with the help of IBM SPSS 21 program. Hypothesis This study shows that the variables of perceived comfort and price have a positive and significant effect on the interest in using public transportation services in the city of Purwakarta.
\end{abstract}




\section{PENDAHULUAN}

Transportasi angkutan umum merupakan bagian dari sistem transportasi perkotaan yang memegang peranan penting dalam menunjang kegiatan masyarakat perkotaan dan fasilitas pendukung terselenggaranya keterkaitan dan interaksi mobilitas penduduk antar bagian wilayah kota yang cenderung semakin meningkat dan intensif.

Keberadaan angkutan umum sebagai transportasi yang sangat penting untuk mendukung kebutuhan masyarakat dan mengurangi kemacetan lalulintas karena mempunyai daya angkut yang besar. Selain itu penggunaan angkutan umum yang baik dapat mengurangi penggunaan kendaraan pribadi. Hal tersebut tidak dapat terlaksana apabila tidak ditangani secara baik dan benar.

Transportasi angkutan umum diselenggarakan dengan tujuan sebagai sarana pelayanan angkutan yang layak bagi masyarakat. Tolok ukur pelayanan yang layak dan baik adalah pelayanan yang murah. aman, nyaman, dan cepat. Jadi, dalam menentukan pilihan jenis angkutan, orang mempertimbangkan berbagai faktor, seperti maksud perjalanan, jarak, waktu tempuh, biaya dan tingkat kenyamanan serta keselamatan.

Saat ini Purwakarta sedang berkembang menuju kota wisata. Tentu saja di perlukan sarana angkutan umum yang memadai, Di Purwakarta ada beberapa jalur trayek angkutan umum kota yang mendukung aktivitas masyarat Purwakarta seperti pada tabel berikut ini:
Tabel 1

Data Angkutan Kota Yang Terdaftar Pada Dinas

Perhubungan, Kebudayaan, Parawisata, Pos Dan

Telekomunikasi Purwakarta.

\begin{tabular}{|c|c|c|c|}
\hline NO & TRAYEK & $\begin{array}{c}\text { KODE } \\
\text { TRAYEK }\end{array}$ & $\begin{array}{c}\text { JUMLAH } \\
\text { KENDARAAN }\end{array}$ \\
\hline $\mathbf{1}$ & 01 & 1 & 132 \\
\hline $\mathbf{2}$ & 02 & 2 & 135 \\
\hline $\mathbf{3}$ & 03 & 3 & 91 \\
\hline $\mathbf{4}$ & 04 & 4 & 63 \\
\hline $\mathbf{5}$ & 05 & 5 & 84 \\
\hline $\mathbf{6}$ & 06 & 6 & 55 \\
\hline $\mathbf{7}$ & 07 & 7 & 99 \\
\hline & Jumlah & $\mathbf{7 4 1}$ \\
\hline
\end{tabular}

Sumber: Dinas Perhubungan, Kebudayaan, warawisata, Pos dan Telekomunikasi Purwakarta.

Dari data yang di berikan oleh Dinas Perhubungan Purwakarta, angkutan umum di Purwakarta masih memberikan peran yang besar untuk gerak hidup ekonomi masyarakat Purwakarta.

Purwakarta memiliki jasa transportasi yang cukup baik dengan adanya angkutan kota, pedesaan dan perbatasan, namun dengan adanya kemajuan teknologi yang tidak bisa dibendung, angkutan umum harus siap bersaing secara ketat dengan transportasi yang mampu memudahkan penggunanya, seperti transportasi online. Berikut gambar dari hasil penelitian yang penulis lalukan sebelumnya. 


\section{Gambar 1 \\ Minat penggunaan jasa transportasi angkutan umum kota di Purwakarta}

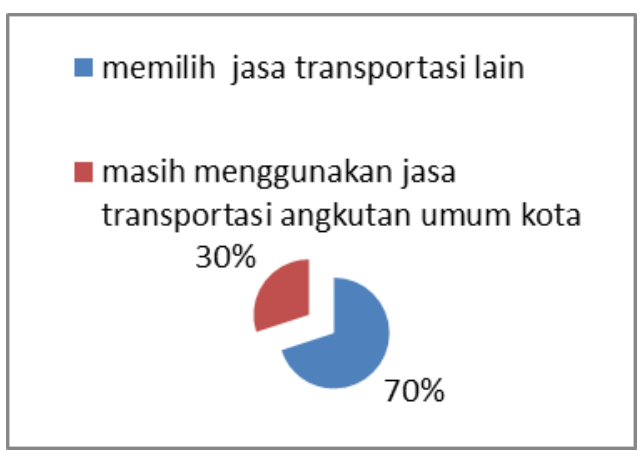

Sumber : oleh peneliti

Dari pengamatan awal yang penulis lakukan pada 20 orang pengguna jasa transportasi angkutan umum, saat ini tidak jarang masyarakat beralih ke kendaraan umum lainya, yang dianggap lebih mampu menjawab masalah transportasi mereka baik dari segi waktu, kegunaan maupun kenyamanan.

Minat Penggunaan jasa transportasi mengalami ketidak stabilan dilihat dari banyaknya angkutan umum kota yang kosong atau tidak berpenumpang. Keadaan ini membuat pengusaha angkutan umum mengalami penurunan pendapatan dan pengoperasian angkutan umum tidak optimal karena kabupaten Purwakarta memiliki rute trayek angkutan umum yang berhimpitan.

Berkurangnya minat penggunaan jasa transfortasi angkutan umum kota di dukung pula dengan banyaknya transportasi online yang sudah ada di Purwakarta, Selain itu kenyamanan semakin tidak di utamakan oleh pemberi jasa angkutan umum kota seperti sering menurunkan penumpang di tengah jalan sebelum tujuan penumpang turun, oper angkutan umum dengan dipungut biaya lagi, ugal-ugalan dijalan, ngetem, angkot mogok bahkan adumulut antar supir angkutan umum lainya sering terjadi, kondisi ini membuat pengguna jasa merasa tidak nyaman.

Angkutan umum perlu memberikan rasa nyaman kepada pengguna baik dari sisi fisik kendaraan maupun non fisik, sehingga dapat menarik minat masyarakat untuk menggunakan salah satu angkutan umum yang telah disediakan, Selain itu juga fasilitas angkutan umum kota yang nyaman akan meningkatkan keselamatan pengguna jasa transportasi. Besar atau tidaknya keinginan masyarakat yang akan menggunakan suatu angkutan umum tergantung pada pelayanan yang diberikan oleh pihak pengelola terhadap pengguna.

Harga merupakan salah satu penentu pemilihan produk atau jasa yang nantinya akan berpengaruh terhadap minat pembelian. Banyak hal yang berkaitan dengan harga yang melatarbelakangi mengapa konsumen memilih suatu produk atau jasa untuk dimilikinya. Konsumen memilih suatu jasa tersebut karena benar-benar ingin merasakan nilai dan manfaat dari jasa tersebut.

Bila suatu jasa mengharuskan konsumen mengeluarkan biaya yang lebih besar dibandingkan dengan manfaat yang diterima, maka yang terjadi adalah bahwa jasa tersebut memiliki nilai negatif. Sebaliknya, apabila konsumen menganggap bahwa manfaat yang diterima lebih besar, maka yang terjadi adalah jasa tersebut memiliki nilai yang positif. 
Para konsumen tertarik untuk mendapatkan harga yang wajar. Harga yang wajar berarti nilai yang di persepsikan wajar pada saat transaksi dilakukan. .

Maka dalam membeli suatu jasa konsumen tidak hanya mempertimbangkan kualitasnya saja, tetapi juga memikirkan kelayakan harganya, Tarif atau harga dasar angkutan umum kota yang berlaku di Purwakarta jarak jauh maupun jarak dekat di tarif dengan harga yang sama, Kesepakatan harga antar pemberi jasa dan pengguna jasa harus saling menguntungkan namun pada faktanya masih banyak pengguna jasa yang merasa harga tidak menggambarkan kenyaman yang diberikan pemberi jasa.

\section{KERANGKA PEMIKIRAN DAN PENGEMBANGAN HIPOTESIS Kenyamanan}

Kolcaba (1992), dalam (Potter \& Perry, 2005) mengungkapkan kenyamanan/rasa nyaman adalah suatu keadaan telah terpenuhinya kebutuhan dasar manusia yaitu kebutuhan akan ketentraman, kelegaan dan transenden. Dengan menggunakan teori dari Katharine Kolcaba dalam "Comfort theory andits application to pediatric nursing" (2005), bahwa kenyamanan mesti dipandang secara holistik yang mencakup empat aspek antara lain :

1) Fisik yaitu rasa nyaman yang berhubungan dengan apa yang dirasakan oleh badan seseorang/sensasi tubuh.

2) Lingkungan yaitu rasa nyaman yang berhubungan dengan lingkungan, atau latar belakang pengalaman eksternal manusia seperti, bunyi, temperatur, warna,dan unsur lainnya.

3) Sosial yaitu rasa nyaman yang berhubungan dengan hubungan interpersonal, hubungan sosial sesama pengguna jasa lainya.

4) Psikospiritual yaitu rasa nyaman yang berhubungan dengan kewaspadaan internal dalam diri sendiri yang meliputi harga diri, konsep diri, seksualitas, makna kehidupan, hingga hubungan

5) terhadap kebutuhan lebih tinggi.

\section{Harga}

Menurut Willian J Stanton yang di terjemahkan oleh Y Lamarto (1989:308) Harga adalah nilai yang disebutkan dalam rupiah dan sen atau medium moneter sebagai alat tukar.

Menurut Stanton (2010:24), terdapat empat indikator yang mencirikan harga, yaitu :

1) Keterjangkauan harga

2) Kesesuaian harga dengan kualitas produk

3) Daya saing harga

4) Kesesuaian harga dengan manfaat

\section{Minat Beli}

Minat beli yaitu sebagai rasa tertarik yang menimbulkan suatu dorongan untuk membeli produk tertentu. Seseorang mempunyai keinginan untuk membeli akan menunjukkan perhatian dan rasa tertarik terhadap produk tersebut. minat membeli ini akan diikuti dengan suatu tindakan berupa perilaku membeli.

Lucas dan Britt (2003) mengatakan bahwa aspek-aspek yang terdapat dalam minat beli antara lain : 
1) Perhatian, adanya perhatian yang besar dari konsumen terhadap suatu produk (barang atau jasa).

2) Ketertarikan, setelah adanya perhatian maka akan timbul rasa tertarik pada konsumen.

3) Keinginan, berlanjut pada perasaan untuk mengingini atau memiliki suatu produk tersebut.

4) Keyakinan, kemudian timbul keyakinan pada diri individu terhadap produk tersebut sehingga menimbulkan keputusan (proses akhir) untuk memperolehnya dengan tindakan yang disebut membeli.

Dapat disimpulkan bahwa aspekaspek dalam minat beli menurut Lucas dan Britt (2003) dalah sebagai berikut:

1) Ketertarikan (interest) yang menunjukkan adanya pemusatan perhatian dan perasaan senang.

2) Keinginan (desire) ditunjukkan dengan adanya dorongan untuk inginmemiliki.

3) Keyakinan (conviction) ditunjukkan dengan adanya perasaan percaya diri individu terhadap kualitas, daya guna dan keuntungan dari produkyang akan dibeli.

Aspek perhatian tidak digunakan karena masih berupa perhatian belum bisa dikatakan sebagai minat, karena tidak adanya dorongan untuk memiliki. Tidak digunakannya keputusan dan perbuatan adalah sah bukan merupakan minat lagi namun adalah menimbulkan reaksi lebih lanjut yaitu keputusan membeli.

\section{Hipotesis}

Hipotesis penelitian dapat diartikan sebagai jawaban yang bersifat sementara terhadap masalah penelitian, sampai terbukti melalui data yang terkumpul dan harus diuji secara empiris. Berdasarkan uraian kerangka pemikiran diatas, diduga persepsi kenyamanan dan harga berpengaruh positif dan nyata secara parsial dan simultan terhadap minat penggunaan jasa transportasi angkutan umum.

\section{METODE PENELITIAN}

Metode yang digunakan oleh peneliti dalam penelitian ini adalah menggunakan metode deskriptif verifikatif. Jenis metode deskriptif yang digunakan adalah metode survey.

\section{Populasi dan sampel}

Populasi didalam penelitian ini adalah pengguna jasa transfortasi Kabupaten Purwakarta. Jumlah pengguna jasa transportasi di Purwakarta tidak diketahui secara pasti maka peneliti akan mengambil sampel sebanyak 100 orang.

\section{Jenis dan sumber data}

\section{Jenis data}

Penelitian ini menggunakan Data kualitatif melalui metode deskriptif. Indikator - indikator untuk ketiga variabel tersebut kemudian dijabarkan oleh peneliti menjadi sejumlah pernyataan sehingga diperoleh data kualitatif. Data ini 
akan dianalisis dengan pendekatan kualitatif menggunakan analisis statistik.

\section{Metode Analisis Data}

Uji validitas menunjukan bahwa semua butir pernyataan memiliki nilai korelasi lebih besar dari nilai $r$ tabel yaitu 0.196. Hal tersebut membuktikan bahwa instrumen penelitian persepsi kenyamanan, harga dan minat beli sudah valid,dan semua instrumen sudah layak digunakan dalam penelitian.

Uji reliabilitas menunjukan bahwa seluruh butir instrument penelitian $\mathrm{X}_{1}$ (persepsi kenyamanan), Variabel $\mathrm{X}_{2}$ (harga) dan Variabel $\mathrm{Y}$ (minat beli). Memiliki Nilai Cronbach Alpha lebih besar dari nilai standar Cronbach Alpha sugiono yaitu 0.060, yang berarti seluruh butir instrumen penelitian sudah reliable.

\section{HASIL DAN PEMBAHASAN}

Pengaruh Persepsi Kenyamanan Terhadap Minat Penggunaan Jasa Transportai Angkutan Umum Kota Di Purwakarta.

Berdasarkan uji t yang telah dilakukan diketahui nilai $\mathrm{t}$ hitung untuk variabel persepsi kenyamanan $\left(\mathrm{X}_{1}\right)$ adalah sebesar $\mathrm{t}$ hitung 5,346 di dukung dengan nilai siginifikan 0,000 yang lebih kecil dari 0,05 atau $5 \%$, maka $\mathrm{H}_{0}$ ditolak $\mathrm{H}_{1}$ diterima, sehingga dapat dikatakan variabel persepsi kenyamanan $\left(\mathrm{X}_{1}\right)$ mempunyai pengaruh yang signifikan terhadap minat beli (Y).

Hasil penelitian ini sesuai dengan penelitian yang di lakukan Sartika dan Zaki (2013) dalam judul 'pengaruh kepercayaan, persepsi kegunaan, persepsi kemudahan dan persepsi kenyamanan terhadap minat pengguna m-banking' dengan output menunjukan sikaf konstruk persepsi kenyamanan berpengaruh positif dan signifikan terhadap minat untuk menggunakam m-banking.

\begin{tabular}{llr}
\multicolumn{2}{c}{ Menurut Kolcaba (1992), } \\
dalam (Potter \&
\end{tabular} 2005 )kenyamanan/rasa nyaman adalah suatu keadaan telah terpenuhinya kebutuhan dasar manusia yaitu kebutuhan akan ketentraman, kelegaan dan transenden. Dalam penggunaan jasa transportasi ini persepsi kenyamanan merupakan suatu pendorong bagi pengguna jasa, jika sudah merasakan kenyamanan makan pengguna jasa akan menggunakan jasa transportasi angkutan umum kota sebagai kebutuhanya. Maka penyedia jasa harus memberikan fasilitas yang nyaman bagi pengguna jasa baik secara fisik maupun non fisik sehingga minat beli jasa meningkat.

\section{Pengaruh Harga Terhadap Minat} Penggunaan Jasa Transportasi Angkutan Umum Kota Di Purwakarta

Berdasarkan uji t yang telah dilakukan diketahui nilai $t$ hitung untuk variabel Harga $\left(\mathrm{X}_{2}\right)$ adalah sebesar $t$ hitung 2,457di dukung dengan nilai siginifikan 0,016 yang lebih kecil dari 0,050 atau 5\%, maka $\mathrm{H}_{0}$ ditolak $\mathrm{H}_{1}$ diterima, sehingga dapat dikatakan variabel Harga $\left(\mathrm{X}_{2}\right)$ mempunyai pengaruh yang signifikan terhadap minat beli (Y).

Hal ini mengindikasikan bahwa minat beli responden dalam menggunakan jasa transportasi angkutan umum kota di Purwakarta dipengaruhi oleh variabel harga 
Harga merupakan unsur penting yang menjadi alat dalam proses pertukaran barang atau jasa oleh konsumen.Dengan demikian adanya harga dapat membantu para pembeli untuk memutuskan cara mengalokasikan daya belinya pada berbagai jenis barang atau jasa. Pembeli membandingkan harga dari berbagai alternatif yang tersedia, kemudian memutuskan alokasi dana yang dikehendaki.

Pengaruh Persepsi Kenyamanan Dan Harga Terhadap Minat Pennggunaan Jasa Transportasi Angkutan Umum Kota Di Purwakarta.

Berdasarkan data primer (kuesioner) yang telah diolah oleh peneliti dengan bantuan SPSS 21, hasil penelitian ini menunjukan bahwa persepsi kenyamanan dan harga bersama-sama (simultan) mempengaruhi minat penggunaan jasa transportasi angkutan umum kota di Purwakarta dimana diketahui nilai koefisien regresi masingmasing variabel bebas memiliki tanda positif, hasil uji hipotesis dari uji $\mathrm{F}$ menunjukan $\mathrm{F}$ hitung sebesar 59,259 dengan taraf signifikan 0,000 yang lebih kecil dari 0,05 atau 5\%. Sehingga dapat disimpulkan bahwa secara simultaan persepsi kenyamanan $\left(\mathrm{X}_{2}\right), \quad \operatorname{Harga}\left(\mathrm{X}_{2}\right)$ berpengaruh signifikan terhadap minat beli (Y).

Kedua variabel tersebut memiliki kontribusi terhadap minat penggunaan jasa transportasi angkutan umum kota di purwakarta. Keputusan membeli sendiri dibentuk oleh individu setelah melakukan proses kognitif yang melibatkan minat, perhatiam, memori, persepsi, membuat alasan, penilaian, membayangkan dan berpikir. Maka untuk meningkatkan minat beli,pengguna jasa harus memberikan kesan positif dari segi kenyamanan fisik maupun nonfisik dan tarif dasar .angkutan umum jarak jauh maupun jarak dekat.

\section{KESIMPULAN DAN SARAN Kesimpulan}

Kesimpulan dari penelitian mengenai pengaruh persepsi kenyamanan dan harga terhadap minat penggunaan jasa transportasi angkutan umum kota di Kabupaten Purwakarta adalah sebagai berikut :
1. Secara parsial persepsi kenyamanan menunjukan adanya pengaruh yang positif dan signifikan. Setiap peningkatan kenyamanan maka akan meningkatkan minat penggunaan jasa trasfortasi angkutan umum kota di Purwakarta.

2. Secara parsial variabel harga menunjukan adanya pengaruh yang positif dan signifikan terhadap minat penggunaan jasa trasportasi angkutan umum kota di Purwakarta.

3. Hasil pengujian hipotesis secara simultan menunjukkan bahwa variabel-variabel dari persepsi kenyamana dan harga secara signifikan berpengaruh terhadap minat penggunaan jasa trasportasi angkutan umum kota di Purwakarta. 


\section{Saran}

1. Penting bagi penyedia jasa trasportasi angkutan umum kota meningkatkan kenyamanan untuk pengguna jasa agar bisa meningkatkan minat pengguna jasa pada angkutan umum kota di Kabupaten Purwakarta.

2. Penting bagi pemerintah dan jasa angkutan umum kota untuk memberikan alternafi pilihan harga untuk pengguna jasa transportasi angkutan

\section{DAFTAR PUSTAKA}

Dimarco, K. K. (2005). Comfort theory and its application to pediatric nursing. Pediatric nursing, 31(3), 187-194.

Wahyuningsih, S. A. (2019). PENGARUH PERSEPSI KEMUDAHAN, KEMANFAATAN DAN RISIKO TERHADAP MINAT NASABAH MENGGUNAKAN INTERNET BANKING DENGAN KEPERCAYAAN SEBAGAI VARIABEL INTERVENING (Studi Kasus Nasabah BNI Syariah KC umum kota seperti membedakan tarif jauh dan dekat.

3. Pemerintah di sarankan meningkatkan kenyamanan fasilitas umum terkait dengan transportasi angkutan umum kota, sehingga pengguna jasa tetap menggunakan transportasi umum sebagai pilihan utama, dan harga tetap harus terjangkau oleh masyarakat.
Yogyakarta) (Doctoral dissertation, IAIN SALATIGA).

Stanton, W. J. (2002). Dasar-dasar pemasaran. Edisi ketujuh. Jakarta: Erlangga.

Imbari, S. (2018). Pengaruh Kualitas Pelayanan dan Kepuasan terhadap Loyalitas (Studi pada Nasabah Tabungan Bank Bca Cabang Purwakarta). Eqien: Jurnal Ekonomi dan Bisnis, 5(1), 40-50.

Hardhy, I., \& Winarta, S. E. (2014). Dasar-dasar pemasaran 